Revista Iberoamericana. Vol. LXVI, Núm. 192, Julio-Septiembre 2000, 625-638

\section{EN BUSCA DE LA MATERIALIDAD PERDIDA: UN APORTE CRÍTICO A LOS PROYECTOS DE RECUPERACIÓN DE LAS TRADICIONES ABORÍGENES PROPUESTOS POR KUSCH, DUSSEL Y MIGNOLO}

POR

\author{
Gustavo Verdesio \\ University of Michigan
}

Uno de los temas que obsede tanto a intelectuales como a ciudadanos de las naciones latinoamericanas es el de la identidad. Una identidad planteada en términos de idiosincracia, de peculiaridad, de rasgos que nos distingan de otras culturas y naciones. La preocupación es razonable y comprensible, debido a la forma en que la cultura occidental se instaló, prepotentemente, en un territorio ajeno donde se desarrollaban culturas notoriamente diferentes a la de los invasores. Por ello, parte de las investigaciones y reflexiones sobre la identidad latinoamericana se han ocupado, en palabras de Mignolo, en indagar "hasta dónde Latinoamérica es parte de Occidente; es el extremo occidente o un espacio donde lo occidental es lo extraño frente a los legados de las culturas Amerindias y Africanas" (“Occidentalización” 27). Es que como afirma Kusch, los latinoamericanos tienen problemas para identificarse con la cultura occidental, debido al carácter híbrido de la cultura latinoamericana: "Por un lado se da un comportamiento cultural coherente enraizado en el pueblo, y, por el otro, otro típicamente occidental, sin que ambos tengan algo que ver" (Kusch, Geocultura 63). La hibridez cultural, entonces, ha sido desde hace tiempo una preocupación de los intelectuales latinoamericanos. Entre las diversas estrategias para lidiar con ella, se ha ensayado repetidamente el estudio de las tradiciones indígenas suprimidas o aplastadas por el discurso oficial (léase occidental) de las naciones modernas del continente. Este interés por las sociedades aborígenes, este intento por restablecer un cierto equilibrio entre las diversas tradiciones culturales que conforman las naciones del continente, se ha manifestado de diversas maneras, pero una de las más recurrentes es el estudio del pasado precolombino y/o colonial de aquellas etnias. En este trabajo me voy a ocupar de algunas de las estrategias formuladas por Kusch, Dussel y Mignolo para el estudio de ese pasado cultural indígena. ${ }^{1}$

Dussel propone un estudio del pasado indígena a través de los documentos de cronistas, tanto occidentales como amerindios, a fin de descubrir los mecanismos y procedimientos mediante los cuales la episteme occidental encubrió la existencia del indígena, su Otro. ${ }^{2} \mathrm{Su}$

\footnotetext{
1 Para un ejemplo reciente de este tipo de actitud de rescate de tradiciones indígenas, puede verse López Mazz (especialmente en página 169), donde el posicionamiento disciplinario no es el de un filósofo o crítico cultural, sino el de un arqueólogo.

${ }^{2}$ La idea es que Europa construyó su propia identidad a partir del “descubrimiento” de América, que hizo posible el surgimiento del proyecto moderno; sin embargo, sus pensadores más influyentes
} 
intento es, entonces, restituir dimensión histórica a ese sujeto excluido, a es Otro de la episteme occidental. Uno de los momentos cruciales de su narrativa es el estudio del encuentro en algunos textos referentes a la conquista de México (Dussel, El encubrimiento 133-159). Allí propone la hipótesis de que los indígenas creyeron, en una primera instancia, que los españoles eran dioses; a esta primera etapa, Dussel la llama "la 'parousía' de los dioses” (136). Para justificar tal interpretación, el filósofo argentino recurre a un estudio de fuentes sobre la posibilidad de la existencia de filosofía y filósofos entre los indígenas latinoamericanos, recurriendo a textos tan disímiles y heterogéneos entre sí como, por ejemplo, los de Garcilaso Inca y Fernando Alva Ixtlizóchitl, que hablan de amautas y tlamatinis $(136,137)$. Estos últimos son los que le interesan en realidad, porque su intención es estudiar el encuentro que tuvo lugar en Tenochtitlán, debido a su carácter paradigmático y a su importancia histórica (136). Pues bien, los mecanismos interpretativos de los tlamatini serán la clave que le permitirá a Dussel interpretar ese choque entre culturas: es el consejo, el marco interpretativo de esos “filósofos” nahuas lo que lleva a Moctezuma a decodificar a los españoles como dioses: "Moctezuma opina-por una conclusión acertada de razón estratégica...- que Cortés es Quetzalcoatl aun en el momento de recibirlo en la ciudad de México” (148).

Dejando de lado la dudosa clasificación de "filósofos” que los tlamatini reciben, vale la pena señalar que muy pocos estudiosos modernos creen a pie juntillas lo que los textos coloniales dicen con respecto al estado de ánimo e interpretaciones indígenas en lo referente a la llegada de Cortés a tierras mexicanas. Baste recordar aquí las objeciones de Inga Clendinnen y James Lockhart (este último citado incluso por Dussel) a este tipo de interpretación, que parece olvidar que los textos estudiados son el producto de un número significativo de años de transculturación y, lo cual sea tal vez más importante, olvida en qué circunstancias los informantes nahuas refirieron sus versiones. Y olvida también ciertos mecanismos culturales de los cuales se sabe muy poco, como por ejemplo el de las profecías y su función en la sociedad. Y tan poco se sabe que lo único que se puede hacer desde el presente es interpretar esas prácticas en el contexto de la información de primera mano (es decir, de origen indígena) disponible (que es bien escasa), como hace Clendinnen en Aztecs. An Interpretation. La propia Clendinnen es la que señala la posibilidad de que esas profecías fueran interpretaciones ex post facto de los luctuosos hechos de la conquista, cuya función sería justificar, retrospectivamente, una serie de hechos de otra manera incomprensibles ("Fierce and Unnatural Cruelty”).

Lo que quiero señalar es, fundamentalmente, el riesgo que se corre al intentar interpretar el pasado indígena a través de los textos producidos en tiempos de la colonia, ya sean estos producidos por oficiales o sujetos españoles, o incluso por informantes aborígenes (lo hayan hecho a pedido de las autoridades españolas o motu proprio). En otras palabras, la pregunta que corresponde hacerse en estas circunstancias es: ¿qué visión del pasado se

(Dussel cita a Habermas y Hegel, en el entendido de que se podría agregar a muchos más) se rehúsan a reconocer la importancia de ese evento, lo cual va produciendo una estrategia de ocultación o encubrimiento del Otro, que consiste en hacer como si ese Otro (a partir del momento del encuentro colonial, del "descubrimiento" de América) nada tuviera que ver con el proyecto moderno y con la historia de Occidente (Dussel, El encubrimiento 27-30). 
puede producir a través de estos medios?, ¿qué tradición cultural se está “recuperando” al tomar a pie juntillas lo que dicen los textos?, ¿qué confiabilidad pueden tener las conclusiones obtenidas a través del estudio de un tipo de evidencia puramente textual?

Una posible respuesta a estas interrogantes podría encontrarse en la propuesta avanzada por Kusch en varios de sus libros, consistente en complementar el estudio de textos de origen indígena con una serie de actividades que él llama, a la manera antropológica, trabajo de campo (Kusch, Geocultura 123 y ss). No contento con analizar textos (aunque lo hace muy bien y de manera menos ingenua que Dussel ${ }^{3}$ ), propone salir al encuentro de los indígenas a fin de preguntarles sobre su cosmovisión, sobre sus concepciones. Consecuentemente, va y lo hace: el producto es ese extraño y olvidado libro, El pensamiento indígena y popular en América, donde indaga en profundidad las categorías de pensamiento de los aborígenes andinos. En otro libro, Geocultura del hombre americano, expone el funcionamiento de ese trabajo de campo, que podría denominarse, según el autor, Antropología Filosófica Americana (141-142). La idea es encarar el diálgo con ese Otro, con el aborigen, de una manera tal que le restituya su condición de sujeto, que por fin le devuelva su dimensión humana:

\begin{abstract}
en virtud del tipo de trabajo antropológico el observado pasa de ser mero objeto y se conviert[e] en sujeto, dado que se refiere a algo existente. A su vez, en tanto que existente tiene un proyecto o posibilidad de ser. Un proyecto que, en suma, se manifiesta como libertad. En ese sentido, lo transinteligible, o así llamado irracional, del punto de vista del conocimiento antropológico, se refiere a esta última constitución en última instancia de un sujeto libre que se concreta como un Otro, que es distinto del observado (Kusch, Geocultura 139-40).
\end{abstract}

Esta relación entre observador y observado, entendida como relación de sujeto a sujeto, se parece mucho a la noción Levinasiana del cara a cara. Sin embargo, en opinión de Dussel, el cara a cara de Levinas nada dice sobre cómo escuchar la voz del Otro (Liberación latinoamericana 8-9), que es, justamente, lo que Kusch intenta hacer. A diferencia del Otro de Levinas, que es incomprensible e incomunicable, porque nos deja en suspenso (Dussel, Liberación latinoamericana 9), en estado de shock, el Otro que Kusch intenta enfrentar en igualdad de condiciones (de sujeto a sujeto, de ser humano a ser humano) puede comunicarnos algo. Este tipo de aproximación al problema del Otro de Occidente, a pesar de su fuerte contenido progresista, plantea ciertos problemas. Por empezar, no queda claro cómo es que el Otro pasa de su tradicional condición de objeto de estudio a la de sujeto si lo que se propone es encarar el intercambio a través de una antropología, disciplina que (muchos ya lo han indicado) ha estado y está al servicio de las instituciones y la propagación de Occidente. ${ }^{4}$ Pero aun en el caso de que fuera posible superar las limitaciones de la antropología (en este caso filosófica) como disciplina, queda todavía un punto muy discutible en la elaboración que del Otro hace Kusch. Me refiero a la permanente utilización que hace de los términos “el indio”, “los indios”, “el indígena” y otros del mismo tenor, que

\footnotetext{
${ }^{3}$ Véase, como ejemplo, su seminal análisis de algunos pasajes del texto de Huamán Poma en El pensamiento indígena.

${ }^{4} \mathrm{Al}$ respecto, ver lo indicado por Said y por Mignolo ("Posoccidentalismo” 683-84), entre otros.
} 
tienen como resultado una generalización de las investigaciones de campo sobre un grupo indígena específico al resto de los grupos aborígenes del continente. ${ }^{5}$ Esta acción de subsumir lo diverso en lo homogéneo, esta presentación uniforme de la vasta gama de grupos indígenas latinoamericanos, difícilmente pueda contribuir a la recuperación del indio en tanto que sujeto. Parece, más bien, una objetivización (porque queda convertido en objeto de discurso) del sujeto que está más allá de las capacidades cognitivas del sujeto occidental (en este caso, Kusch mismo).

Otro problema (relacionado con lo ya dicho) a tener en cuenta es la extrema confianza que Kusch tiene en este método de obtener información (mediante entrevistas que él llama trabajo de campo) en tanto que medio para recuperar una tradición cultural, una forma de ver el mundo. Sobre todo, parece creer que lo que digan los indígenas contemporáneos es la última palabra, la verdad verdadera sobre el pasado y las cosmovisiones indígenas. Todo su trabajo de recuperación de tradiciones culturales aborígenes (que él estudia como si se tratara de una sola) está basado en la absoluta confianza en la palabra del entrevistado, complementada por los textos coloniales a que se aludió más arriba. Como se verá más adelante, no siempre lo afirmado por los entrevistados o los textos refleja lo que en realidad ocurría.

Del mismo modo, Dussel (sin llegar a proponer, como Kusch, el trabajo de campo) propone un contacto con el Otro, un cara a cara que supere el de origen Levinasiano, a través de un contacto con la Exterioridad, es decir, con aquellos que habitan más allá del ser o de la totalidad (Filosofía de la liberación 56). ${ }^{6}$ Esto implica una conciencia ética: escuchar la voz del Otro con respeto, porque todo lo ignoramos sobre él (76-77). Este énfasis en la voz lo acerca, también, a las ideas de Kusch con respecto al testimonio oral del pensamiento indígena, en el sentido de que ambos tienen fe en la palabra del Otro (Dussel, Filosofía de la liberación 62).

En este trabajo, sin embargo (y sin desdeñar el recurso a la voz del Otro), voy a abogar por un estudio de la materialidad a través de los objetos, que complemente al trabajo de campo de Kusch y al cara a cara de Dussel. Antes de hacerlo, sin embargo, es conveniente señalar que las cosas, los objetos, no son un elemento privilegiado en el corpus filosófico de ambos autores. Por el contrario, parece percibirse en ambos una cierta aversión al mundo

\footnotetext{
${ }^{5}$ Esto puede verse en todos sus trabajos, pero baste como muestra un párrafo extraído de América profunda, donde estos vocablos aparecen tres veces en cinco líneas: "Pero en este sentido nos aventaja el indio. Por eso resulta interesante el caso que nos trae Kubler, cuando nos dice que los indios consideraban a Cristo y al diablo como hermanos. Y eso es verdad, porque si el indio suprimiera al diablo y lo sacara de su conciencia, ese mundo adquiriría demasiada tensión y perdería su arraigo" (176, énfasis mío) .

${ }^{6}$ Esto debe entenderse del modo siguiente: el ser, como creación filosófica del mundo griego, es una ontología de la totalidad. Lo que está fuera del ser, no existe: es el no-ser. Así interpreta el aforismo de Parménides ("lo que es, es, lo que no es, no es”) y la mayéutica socrática (que es un método para extraer conocimiento que ya estaba en el discípulo, o en el peor de los casos en el topos uranos): como reproductores ideolígicos del ser, de lo mismo; como artefactos negadores del Otro, que es nada porque se encuentra fuera de la totalidad (Dussel, Liberación latinoamericana 15-17). Del mismo modo, en el terreno político y cultural, el ser griego llegaba sólo hasta las fronteras del mundo helénico: más allá estaba la periferia, los bárbaros, el no-ser (Filosofía de la liberación 15-16).
} 
de los objetos. Especialmente en el caso de Kusch, quien sostiene que el domicilio está constituido, para los occidentales, por las cosas (Geocultura 21). En su conocida distinción entre el estar (entendido como acontecer previo a la ontología) y el ser (la forma de ser alguien al modo occidental), las cosas son instrumentales para el sujeto occidental que intenta ser alguien (28): sin el utensilio, sin la cosa, el sujeto occidental no es nada (51). Este rodearse de cosas es, según el filósofo argentino, una forma de escaparle al espanto que provoca el mero estar, el vivir entendido como mero acontecer (55-56). Llega incluso a decir que la actividad cultural no deriva en cosas sino en creaciones (68), lo cual podrá ser muy poético, pero se trata de una afirmación fácilmente refutable: los seres humanos producen objetos por medio de actividades. Negar esto, incluso por medio de un lenguaje poético o creativo, es peligroso si lo que se intenta es reflexionar seriamente. ${ }^{7}$

Dussel, por su parte, si bien no es tan adverso a los objetos, los pone en segundo plano. Su filosofía sostiene que, para el ser humano, antes de que hubiera mundo (de los objetos) hubo otro ser humano: la madre. El primer contacto que tiene un ser humano con lo exterior a él/ella es otro ser humano, no un mundo de objetos (Filosofía de la liberación 30). Su filosofía se va a centrar principalmente, entonces, en las relaciones entre seres humanos, dejando en un segundo plano a la proxémica (la relación entre ser humano y las cosas, organizadas en un universo de sentido o mundo) (34). Los objetos, entonces, son parte de un mundo, que es, a su vez, una totalidad. Como lo que le interesa a Dussel es la exterioridad, lo que está fuera de la totalidad (del ser), es comprensible que los objetos tengan un papel secundario en su aparato filosófico, en tanto que mediaciones (cosas que "sirven para”) (4445). El cosmos (el mundo de la naturaleza que comprende tanto a los entes que son parte del mundo como a los que nos son desconocidos) es el escenario en el cual el sujeto occidental debe relacionarse con el Otro, es el teatro donde debe escuchar su voz y prestarle servicio (125). Pero así como dice esto, también afirma lo siguiente: “La esencia de la flecha, y no de la madera real del árbol, es la totalidad mundana o cultural dentro de la cual cumple una función determinada (la de servir para la caza, por ejemplo): el instrumento es un momento de la esencia humana” (163). Para el objetivo principal de este trabajo (la discusión de métodos de recuperación del pasado indígena, de sus tradiciones culturales), esta afirmación es importante porque permite vislumbrar la importancia que podría tener el estudio de los objetos en tanto que medio para descifrar o recuperar el pasado cultural de las culturas aborígenes.

Antes de entrar en este tema, es conveniente volver a lo que realmente le interesa a Kusch: el estudio del pensamiento indígena, sus raíces culturales, porque en su opinión, ese es el verdadero sujeto cultural de América (124) y, a diferencia de los occidentales, ese sujeto se sustrae al "patio de los objetos" (125). Su pensamiento, entonces, es lo que debe ocupar la atención del investigador: "La búsqueda de un pensamiento indígena no se debe sólo al deseo de exhumarlo científicamente, sino a la necesidad de rescatar un estilo de pensar que, según creo, se da en el fondo de América y mantiene cierta vigencia en las poblaciones criollas” (Kusch, El pensamiento indígena 11). Mignolo complementa este

\footnotetext{
${ }^{7}$ Más adelante en este trabajo se tratará el tema de la actividad cultural humana y su relación con los objetos que produce.
} 
programa del siguiente modo: “aceptar la ubicación de las herencias del pensamiento indígena y las huellas de sus transformaciones desde la colonia hasta nuestros días”, agregando que "habría que reflexionar no sólo en lo que Kusch trata de rescatar, sino en cómo propone hacerlo” (“Occidentalización” 31). Lo que quiere decir Mignolo es que “exhumar científicamente” implicaría imponer un estilo de pensar sobre otro estilo de pensar; en cambio, “'rescatar un estilo de pensar’ implica la búsqueda de ciertas raíces, ciertas referencias o ciertos puntos de apoyo que no sean, precisamente, las raíces y los puntos de apoyo que dieron lugar a la configuración de estilos de pensar entre los cuales se cuenta la posibilidad de exhumar científicamente otros estilos de pensar" (31-32). Lo primero a tener en cuenta es el carácter metafórico del uso del verbo “exhumar” en el pasaje citado: es evidente que el pensamiento no se guarda ni se esconde bajo tierra. Esta aclaración, aparentemente trivial, es tal vez oportuna porque el uso de expresiones poco precisas o inadecuadas es un error que se comete frecuentemente en el campo de los estudios humanísticos; error que tiene como consecuencia, a veces, el oscurecimiento o descarte de procedimientos, ideas o interpretaciones que podrían utilizarse con beneficio. En este caso, el uso del verbo "exhumar" que hacen Kusch y Mignolo está cargado de connotaciones negativas: aparece como representante de un saber, de una forma de interpretar la realidad que oprime o niega al sujeto indígena al convertirlo en un objeto a ser estudiado. Gracias a esta caracterización negativa, se deja fuera de toda posible agenda de investigación, precisamente, a lo que voy a proponer en este trabajo: echar mano a la excavación, a la exhumación no ya metafórica del pensamiento, sino efectiva y tangible de objetos producidos por las culturas indígenas.

Antes de pasar a abogar por la necesidad de recurrir a la arqueología para comprender el pasado indígena, conviene llamar la atención sobre algunas ideas de Mignolo sobre la cuestión de la materialidad. En su libro The Darker Side of the Renaissance propone prestar especial atención a la materialidad de los objetos portadores de signos. Consecuentemente, se embarca en un estudio comparativo de los libros europeos y su correlato indígena, los amoxtlis mexicas (69-122). Es a partir de las diferencias materiales entre esos objetos (que comparten la función de portar signos, pero cuyas conceptualizaciones de tal función difiere diametralmente de una cultura a la otra) que Mignolo propone un estudio crítico de las concepciones occidentales sobre la cultura de los Otros y sobre el valor que se asigna a sí misma. Sin embargo, su análisis se limita a comparar lo que le parece comparable: dos tipos de objetos que tienen una función aparentemente análoga (aunque no igual) en dos culturas diferentes. La materialidad que le interesa, entonces, es aquella que le permite comparar artefactos indígenas con artefactos europeos: su análisis puede existir, solamente, porque encuentra un correlato aborigen para el objeto occidental "libro". Lamentablemente, la comparación de objetos similares en las dos culturas estudiadas es lo que le impide preguntarse por las prácticas sígnicas de aquellas culturas indígenas sin amoxtlis u otro tipo de objetos portadores de signos: si lo que se busca es un equivalente del artefacto "libro" en una cultura indígena, es comprensible que la ausencia de tal artefacto en esa cultura aborigen determine la imposibilidad de compararla con la europea. La materialidad que le interesa a Mignolo es, entonces, la que, paradojalmente, le cierra la puerta a la posibilidad de estudiar las culturas que carecían de esos objetos materiales, llámense libros o amoxtlis. 
Las culturas que no produjeron esos objetos quedan descartadas en tanto que posible objeto de estudio.

La materialidad que me interesa es de distinta índole: no sólo la de los objetos portadores de signos, sino la de todo objeto cultural indígena. Para un tipo de proyecto que busca dar cuenta de las cosmovisiones, las organizaciones sociales y las vidas cotidianas de los pueblos indígenas que no produjeron objetos portadores de signos, la arqueología puede prestar una invalorable ayuda. Su capacidad de interpretar los objetos en tanto que relicto de actividades humanas, es decir, como testimonio de acciones que lo produjeron, que le dieron origen, es fundamental para reconstruir las prácticas humanas de las culturas precolombinas. Mi intención no es, entonces, privilegiar a los objetos qua objetos, sino más bien estudiarlos como resultado, como punto final de una actividad humana concreta. Si bien la arqueología no es una ciencia exacta —e, incluso si lo fuera, estaría expuesta a la subjetividad del investigador y de la episteme en la que produce conocimientorecurrir a ella puede ser útil para descifrar el pasado indígena de una manera más completa. Por ejemplo, puede evitarle a los investigadores caer en el mismo error homogeneizador de Kusch, al recordarles (mediante el estudio de casos concretos) que las culturas indígenas eran muy diferentes entre sí, incluso dentro de grandes unidades político-culturales, como es el caso del estado Inca. Puede, también, si lo que se quiere es recuperar un pensamiento (que es lo que realmente les interesa a Kusch y a Mignolo), clarificar ciertas ideas con respecto a diversos de temas. Por ejemplo, la forma en que se concebían - y funcionabanel poder religioso o el control político en los estados precolombinos, por ejemplo, el de los Incas. ${ }^{8}$ Si se cree a pie juntillas lo que dicen las crónicas, se correrá el riesgo de suponer que aquel estado practicaba el mismo tipo de mecanismo de control a todos los pueblos y regiones sometidos a su poder. Las investigaciones arqueológicas más recientes parecen demostrar lo contrario: que los Incas no ocupaban todos los territorios de la misma manera y que sus mecanismos de control político-administrativo variaban, también, según los casos. $^{9}$

Lo que me interesa, en realidad, es la reconstrucción de un contexto cultural, de un complejo de actividades sociales que vaya más allá del mero estudio del pensamiento y de las concepciones indígenas. Sin ese contexto es difícil, a veces, entender realmente la naturaleza y contenido de ese pensamiento que Kusch y Mingolo intentan recuperar. Lo que estoy proponiendo aquí no es una arqueología del saber, sino una arqueología que trascienda la búsqueda de las meras concepciones o formas de pensamiento de las culturas indígenas y se concentre en el estudio de la vida entendida como complejo de concepciones y prácticas

\footnotetext{
${ }^{8}$ Para un estudio de la diversidad y heterogeneidad en materia de creencias religiosas en el estado Inca, puede verse el libro de Sabine McCormack. Allí también puede verse la constante tensión entre los distintos grupos de aborígenes andinos y los Incas en materia política y administrativa.

${ }^{9}$ Para un estudio de las diferentes formas y grados de ocupación Inca de las provincias conquistadas, puede verse el libro editado por Malpass. Esta colección es sumamente útil para entender el modus operandi del joven estado Inca en materia de ocupación y para el estudio crítico de los materiales etnohistóricos, que son confirmados o negados (según los casos) por la evidencia arqueológica. Esta combinación de herramientas (etnohistoria y arqueología) para el estudio del pasado es muy similar a lo que voy a proponer al final de este trabajo.
} 
humanas. En suma, lo que estoy proponiendo es, más bien, una arqueología del vivir. ${ }^{10}$ La forma de encararla es a través de la incorporación de los esfuerzos de los arqueólogos, que tanto tienen para aportar al conocimiento de las culturas precolombinas antes y después del choque de culturas. Sumando esfuerzos, entonces, es que se podrá, aunque más no sea en ínfima medida, llegar más cerca de una comprensión cabal de esos saberes locales (de los diversos grupos y sujetos indígenas) entendidos como vivir. Un vivir que los investigadores del presente recibimos en forma de materialidad, a través de los relictos de actividades humanas que, desandando un camino, sirven de guía hacia las prácticas que los produjeron.

La idea es entonces recuperar las vidas de esos sujetos, su experiencia vital, de modo tal que se las pueda incorporar como aporte vivo a la experiencia vital del presente. Con esto quiero decir que su lugar debe ser, en nuestro presente, el de un sujeto, aunque esta vez la comunicación no pueda (por razones obvias) existir, dada la imposibilidad del cara a cara. Pero lo que sí se puede hacer es darle el status de sujetos y aceptar su conocimiento entendido como contribución que un grupo local hace al saber de la humanidad toda. Para ello, es necesario, ahora sí, evitar la exhumación, en el sentido (metafórico) que le dan Mignolo y Kusch, de su conocimiento. Sin ese respeto básico al Otro de que habla Dussel, será imposible tomar seriamente los posibles aportes de esos saberes locales a la humanidad. Es a partir de ese respeto que se debe encarar la investigación: más como una praxis destotalizadora, exteriorizante, de solidaridad con el Otro, que como una empresa meramente académica.

Que el Otro tiene mucho para enseñarle a Occidente lo prueban los casos de arqueología experimental como el que está conduciendo Clark Erikson en varias zonas de los territorios inundables de lo que hoy es Bolivia (ver su "Prehistoric Landscape” para una descripción más completa del procedimiento). El equipo a su cargo está llevando a cabo ciertas prácticas de explotación de la tierra que fueron abandonadas un poco antes de la llegada de los españoles. El tipo de agricultura practicada se conoce en la literatura especializada como "raised fields" y consiste en levantar artificialmente la altura de las tierras de sembrado mediante la acumulación de tierra y despojos, de modo tal que protejan los cultivos en caso de que ocurra alguna inundación. Esta operación se complementa por medio del diseño y construcción de una red hidráulica de canales que comunican las diferentes parcelas elevadas artificialmente. Los resultados obtenidos a partir de la reconstrucción de los “raised fields” son muy positivos: se evita la anegación del territorio durante la temporada de las lluvias y se facilita la irrigación durante la estación seca. El trabajo que insume la construcción de estas estructuras elevadas y sus canales es considerable, pero su mantenimiento posterior exige muy pocas horas de trabajo. Lo más interesante del

10 En este sentido, lo que propongo no se diferencia demasiado de la idea que esboza Kusch: la necesidad de estudiar al indígena dentro de su coherencia cultural (Geocultura 84); es decir, en un marco tan complejo que no vacilo en llamar "vida.” También aboga por este tipo de proyecto de investigación en el pasaje que habla de cultura en tanto que estrategia para vivir (98) y, más concretamente, en el pasaje en que habla de la necesidad de recuperar el vivir mismo (100). Lamentablemente, el resto de su libro se concentra, tan sólo, en la recuperación del pensamiento indígena, olvidando el proyecto más amplio que acabo de mencionar. Algunos podrán argüir, sin embargo, que su noción de pensamiento en tanto que filosofía que implica un estilo de vida (El pensamiento 16) lo acercaría considerablemente al tipo de investigación que estoy proponiendo. 
caso, sin embargo, es que este tipo de obra de ingeniería está al alcance de grupos sociales pequeños, tales como la unidad básica familiar. Los números señalan que los resultados de las cosechas obtenidas a través de este tipo de explotación de la tierra son satisfactorios en comparación con otras formas de agricultura que se usan contemporáneamente en terrenos de similares características (todos estos datos están tomados de Erikson, "The Social Organization”). De modo que aun si el observador se sitúa de este lado del encuentro cultural, aun desde una perspectiva que privilegie los estándares Occidentales de una lógica capitalista, los resultados obtenidos a través del uso de esta técnica (o saber) indígena son satisfactorios.

Lo que se debe, entonces, es intentar rescatar este tipo de saberes que son, en realidad, mucho más que una mera forma de pensar o concebir el mundo, sino que son, también, una acumulación de prácticas sobre el territorio. Un territorio que, al ser interpretado y practicado por el ser humano, se convierte en un paisaje (Kusch, Geocultura 140). La arqueología, que permite indagar lo que quedó en el territorio como relicto de actividades humanas, es una herramienta indispensable para la recuperación de esa acumulación de prácticas entendidas como memoria del paisaje o capital paisajístico (Erickson, “The Social Organization” 381).

Otro ejemplo que podría invocarse es el que ofrece Taussig en su estudio sobre los "indian carriers" de Colombia durante el siglo XIX, que cargaban a sus espaldas a los españoles cuando necesitaban viajar por zonas inhóspitas (287-335). Se trataba del tránsito de caminos que ya existían cuando llegó el conquistador, los cuales ponían en comunicación las redes de comercio entre los distintos grupos hasta la llegada de los españoles (296), momento en el que ese tipo de comunicación entre los aborígenes se abandonó, como ocurrió con la mayoría de las instituciones y prácticas indígenas que se intentó sustituir por otras de origen europeo. El reciclaje decimonónico de esas rutas abandonadas es un caso más que ilustra esa acumulación de prácticas y conocimientos sobre el paisaje mencionado más arriba.

Estos saberes locales ancestrales son, entonces, el punto de apoyo que estudiosos como Kusch y Mignolo están buscando, a fin de fundar sus propios discursos. Me refiero especialmente a lo expresado por el último nombrado, quien afirma que el proyecto de Kusch "nos invita a fundar formas de pensamiento sobre estilos que habían sido considerados como interesante material etnográfico pero no como formas de pensamiento en su propio derecho” (“Occidentalización” 32). La estrategia queda clara: el pensamiento indígena será una de las tradiciones, una de las raíces que le permitirán al intelectual periférico construir su propia situación de enunciación de cara al proceso de occidentalización (39). Pero lo indígena por sí solo no parece ser suficiente para la generación de nuevos lugares de enunciación; es la zona fronteriza entre culturas, el espacio cultural entre-medio lo que, según Mignolo, ofrece la posibilidad de hacerlo. En un pasaje que analiza el problema de la occidentalización de América Latina, que la convierte en "una entidad geocultural creada por los diseños imperiales”, el citado crítico sostiene que es “en esa encrucijada (o mejor, en esa zona fronteriza), que se produce la tensión entre lo que se considera propio y lo que se considera ajeno" ("Posoccidentalismo" 681). Si la zona fronteriza entre dos culturas es un lugar privilegiado para la producción de conocimiento, no es sorprendente que el siguiente paso sea la celebración de un nuevo tipo de zona fronteriza para el intelectual 
latinoamericano: "la emergencia de un nuevo tipo de trabajo, ligado a la creciente emigración de intelectuales desde América Latina a Estados Unidos, que inaugura una espistemología fronteriza entre las expectativas epistemológicas de las ciencias sociales y las expectativas políticas de la reflexión intelectual” (686). Para clarificar aun más su opinión, véase el siguiente pasaje:

la incorporación de la barbarie en los términos negados por la civilización, es lo que permite trascenderla, no reivindicando su opuesto (la barbarie) sino reivindicando la fuerza de la frontera que crea la posibilidad de la barbarie de negarse a sí misma como barbarie-en-la-otredad; de revelar la barbarie en la mismidad que la categoría de civilización ocultó; y de generar un nuevo espacio de reflexión que mantiene y trasciende el concepto moderno de razón (688).

Vivan las fronteras, entonces. Y vivan los que, como Anzaldúa, ${ }^{11}$ hacen posible "la generación de una epistemología de frontera DESDE varios espacios del Tercer Mundo configurado por diferentes legados coloniales, PARA el conocimiento y la civilización planetaria (e.g.: no una espistemología para los marginados, o del Tercer Mundo para el Tercer Mundo...)” (688-89). ${ }^{12} \quad \mathrm{Y}$ en medio de la globalización actual, en medio de esta epifanía del conocimiento fronterizo, es que el Otro empieza a desaparecer y lo reemplaza el subalterno: “En esta rearticulación, la cuestión de la otredad pierde relevancia y comienza a ser desplazada por estructuras económicas globales y políticas transestatales que hacen más visible la 'subalternidad' que la otredad; subalternidad, claro está, que sobrepasa el marco de las clases sociales y crea las condiciones para la multiplicación de movimientos sociales y para la rearticulación de la sociedad civil” (690).

El pasado cultural aborigen, entonces, sigue un extraño itinerario que va desde su celebración respetuosa, para luego ser apropiado por la nueva estirpe de intelectuales latinoamericanos en la diáspora que, una vez que lo han invocado, lo olvidan alegremente alegando que el Otro ya no existe, que lo que hay es subalternos. Lo que ahora importa no es tanto esas tradiciones indígenas del pasado, sino los sujetos híbridos, fronterizos del presente. Especialmente aquellos que obtuvieron un título universitario y tienen la posibilidad de desplazarse libremente por diversas latitudes. ${ }^{13}$ Si se presta la suficiente atención, se verá que mediante un sutil pase mágico, gracias a la aparición en escena del

11 Cuyas ideas habrían producido, según Mignolo, un giro similar al que produjo Descartes con su Discurso del método. ("Posoccidentalización” 693). Si bien es cierto que esta afirmación es, cuando menos, discutible, sólo se la cita aquí para dar una idea del entusiasmo de Mignolo por las fronteras y los fronterizos.

${ }_{12}$ Nótese que lo que más le interesa a Mignolo es recuperar a Latinoamérica como lugar productor de conocimiento, no como mero objeto de estudio (Posoccidentalismo 683-84), lo cual es una pretensión legítima. Lo que plantea dudas y parece más merecedor de cuestionamientos es el sujeto que Mignolo parece proponer como agente productor de ese conocimiento local: a veces es el intelectual latinoamericano (presentado como parte de un nuevo movimiento social o grupo de interés- en 683), a veces el sujeto subalterno, como ya veremos. El Otro absoluto, ese que siempre ha quedado fuera de la lista de productores de conocimiento, vuelve a estar ausente.

13 Abril Trigo, analizando ciertas posturas poscoloniales con respecto al lugar de enunciación fronterizo, dice: "Es fácil, sin duda, incurrir en la fetichización de ese no-lugar fronterizo en tanto 
subalterno, el Otro (sin comillas y con mayúscula) vuelve a su status de no-existencia, de no-ser: queda fuera del horizonte cognitivo de los investigadores del presente. ${ }^{14}$ Pero el Otro sigue existiendo incluso en tiempos de globalización e intelectuales diaspóricos: no todo el mundo vive en la frontera, no todo el mundo presenta el mismo grado de hibridez.

Mignolo podría argumentar que ese Otro absoluto, incontaminado por Occidente, no existe ya. Mi respuesta a tal objeción sería reconocer que sí, que hoy todo el mundo es híbrido en mayor o menor medida, pero que es irrelevante fijarse en cuán puros o impuros son los sujetos en términos culturales (ya concedí que las culturas, en la expansión de Occidente que termina en la globalización, no pueden ya estar en estado de pureza). Lo que más divide a la gente, lo que la vuelve dominadora o dominada, sigue siendo, todavía, el poder económico, acompañado de su aliado de siempre, el poder político. Lo importante, entonces, es ver quién oprime a quién, quién es rico y quien es pobre. Y está bien claro que no todos los sujetos híbridos son igualmente pobres u oprimidos. Para ilustrar estas afirmaciones, bastará un ejemplo. Cuando Mignolo argumenta por una situación enunciativa híbrida, presenta el caso de Kusch quien, en su opinión, gracias a sus posturas filosóficas con respecto a los amerindios, no debería ser clasificado como un sujeto occidental que observa al indígena como a un Otro. Para Mignolo, Kusch no sería ni el "Mismo" europeo (o criollo) ni el "Otro" indígena: en su esquema conceptual, el Otro aborigen es parte del país, de la cotidianeidad de Kusch y por ello el "nosotros” y el “ellos” se subsumen en una totalidad que los comprende. Lo ubica, entonces, en una situación de enunciación que podría definirse como un tercer espacio en el que todos componen un "nosotros" más amplio: el que abarca a los herederos de un legado colonial (The Darker Side 14). Sin embargo, sería irresponsable (o ingenuo) comparar la situación del filósofo argentino con la de los indígenas objeto de su estudio. En Latinoamérica hay, todavía, grupos que viven en condiciones infrahumanas, bajo los niveles de pobreza más abyectos; grupos que viven más allá de las fronteras del Ser Occidental de que habla Dussel. ${ }^{15}$ Kusch y Mignolo, herederos de la misma situación colonial que oprimió y oprime a los indígenas

locus privilegiado de producción de conocimiento, y de los sujetos instalados en él como los augures de tiempos y pensamientos por venir” (79). Creo que la estrategia de Mingolo incurre en esa fetichización.

14 El recurso de reivindicar etnias oprimidas como pretexto para justificar sus agendas políticas particulares, es bastante tradicional entre los criollos latinoamericanos, como bien señala Angel Rama (12).

15 Mignolo objeta a la concepción dusseliana del Otro (The Darker Side 12) porque sostiene que es parte de una ontología muy rígida que no deja espacios intermedios, intersticios a partir de los cuales puedan surgir sujetos subalternos híbridos, que como ya hemos visto son su preocupación principal. Creo que aquí corresponden dos puntualizaciones. La primera, tiene que ver con lo que creo es un error de percepción por parte de Mignolo. Dussel no propone una ontología rígida, solamente la describe: es occidente el creador de esa ontología. Dussel lo que hace es explicar su funcionamiento y proponer que la superemos. La frontera que quiere abolir Dussel es aquella que, en palabras de Abril Trigo, “delimita el Ser” (82). La otra puntualización es la siguiente: la definición de subalterno que Mignolo aporta no es la única posible. Klor de Alva, por ejemplo, admite, en el modelo que propone para explicar las situaciones coloniales, la coexistencia del subalterno y del Otro. Aunque no lo nombre como Otro, el indígena (a quien define como el colonizado debido a su condición abyecta) 
latinoamericanos, no han sido, sin embargo, considerados como Otros de la cultura occidental; no han sido relegados al mundo del no-Ser. Por eso, sin ignorar las subjetividades emergentes en este mundo globalizado, insisto en la categoría del Otro, al menos en la elaboración que le dio Dussel, porque nos permite, a los investigadores del presente, encarar el estudio de las tradiciones culturales indígenas (notoriamente oprimidas, notoriamente depauperadas) de una manera más adecuada, al indicar estrategias para dar cuenta de lo indecible, de lo no-existente para el mundo occidental (el mundo del Ser). Y una de sus recomendaciones es que nos abramos a la manifestación del Otro, o más bien que estemos atentos a la exposición del Otro, a la forma en que se nos presenta, en que se expone a nosotros, interpelándonos (Filosofía de la liberación 149).

El Latin American Subaltern Studies Group afirma la necesidad de una práctica teórica (Rabasa y Sanjinés x). Sin negar en absoluto esa necesidad sino más bien complementándola, propongo desde aquí una estrategia que contribuya a que aquel Otro de hace 400 o 3000 años quede expuesto (materialmente, como quiere Dussel) ante nosotros, sujetos del presente, interpelándonos. Para hacerlo, no alcanza con estudiar el testimonio de los indígenas actuales y lo que dicen los textos coloniales; hay que apelar, además, a todos los recursos disponibles: uno de ellos, la arqueología, el estudio de los objetos producidos por una cultura, es una herramienta indispensable que los estudios coloniales no están usando lo suficiente. Sólo así, mediante el uso de una combinación de recursos para la investigación del pasado (entre los cuales está la arqueología, que nos confronta con la materialidad de los relictos de vida), es que estaremos en condiciones algo mejores para exponer (otra vez: en forma menos verbal que material) a ese Otro ancestral.

La idea es, entonces, intentar una arqueología del vivir que, sin descansar total y exclusivamente en la arqueología como ciencia auxiliar, la trascienda conservando su tendencia a concentrarse en el estudio de la materialidad. De lo que se trata es de enfocar todas las baterías, todos los recursos disponibles, hacia la recuperación de las trazas materiales (y de las otras) de las tradiciones indígenas, de manera tal que tengan un efecto similar al de la exposición de que habla Dussel.

Lo que propongo, entonces, no es ya indagar en el pasado para poder encontrar puntos de apoyo que legitimen la situación de enunciación actual de los intelectuales periféricos, sino más bien rescatar, en el sentido estricto del término, un conocimiento y una experiencia vital que pueda enseñarle algo a todo el mundo (sobre todo a Occidente) sobre la vida. De este modo, no serán sólo los intelectuales latinoamericanos los que aparecerán como productores de conocimiento, sino que también el Otro, el indio, aparecerá como sujeto en vez de objeto. Algo así, me parece, quería lograr Kusch por medio de su trabajo de campo;

encaja perfectamente en esa categoría. Los mestizos, las mujeres y otros grupos de la sociedad colonial (entendidos como subalternos en el modelo de Klor de Alva) estaban en desventaja relativa con respecto a los españoles y a los criollos, pero según dicho crítico, de ninguna manera puede considerárselos como colonizados, debido a su participación libre en las reglas de juego de la vida social colonial y, no menos importante, a su adscripción a los valores culturales de origen europeo. Los indígenas, por su parte, estaban totalmente por fuera de esa organización social (Dussel diría que vivían en el reino del no-Ser) y su situación en las estructuras de poder era la más baja (255). En el modelo de Klor de Alva hay, entonces, distintos grados de sujeción y marginalidad (270). En el de Mignolo, parecería que no. 
algo así propone Dussel con su versión del cara a cara y con su praxis revolucionaria en todos los frentes sociales; algo parecido buscaba Mignolo en sus trabajos sobre la época colonial; algo similar parece estar proponiendo el colectivo Latin American Subaltern Studies Group: la vindicación de, y la solidaridad con, un Otro entendido como sujeto, como nuestro igual. ${ }^{16}$

Bibliografía

Anzaldúa, Gloria. Borderlands/La Frontera: The New Mestiza. San Francisco: Spinster/ Aunt Lute, 1987.

Beverley, John. "Introducción”. La voz del Otro: Testimonio, subalternidad y verdad narrativa. John Beverley y Hugo Achugar, eds. Lima/Pittsburgh: Latinoamericana Editores, 1992. 7-18.

Clendinnen, Inga. Aztecs. An Interpretation. [1991]. Cambridge: Cambridge University Press, 1995.

“"Fierce and Unnatural Cruelty”: Cortés and the Conquest of Mexico”. New World Encounters. Stepehn Greenblatt, ed. Berkeley: University of California Press, 1993. 12- 47.

Dussel, Enrique. Filosofía de la liberación. Bogotá: Universidad Santo Tomás, 1980. El encubrimiento del Otro. Hacia el origen del mito de la modernidad. Quito: Ediciones ABYA- YALA, 1994.

y Daniel Guillot. Liberación latinoamericana y Emmanuel Levinas. Enrique Dussel y Daniel Guillot. Buenos Aires: Editorial Bonum, 1975.

Erickson, Clark. "The Social Organization of Prehispanic Raised Field Agriculture in the Lake Titicaca Basin”. Economic Aspects of Water Management ind the Prehispanic New World. Research in Economic Anthropology. Supplement 7. Vernon Scarborough y Barry Isaac, eds. Greenwich, CT/Londres: Jai Press, 1993. 369-426.

"Prehistoric Landscape Management in the Andean Highlands: Raised Field Agriculture and its Environmental Impact”. Population and Environment 13/4 (1992): 285- 300.

Klor de Alva, J. Jorge. “The Postcolonization of the (Latin) American Experience: A Reconsideration of 'Colonialism', 'Postcolonialism', and 'Mestizaje”. After Colonialism. Imperial Histories and Postcolonial Displacements. Gyan Prakash, ed. Princeton: Princeton University Press, 1995. 241-75.

Kusch, Rodolfo. El pensamiento indígena y popular en América. [1970]. Buenos Aires: Hachette, 1977.

Geocultura del hombre americano. Buenos Aires: Fernando García Cambeiro, 1976.

${ }^{16}$ Me refiero a una solidaridad similar a la que menciona Beverley con respecto al testimonio (8-9) y a la que postulan Rabasa y Sanjinés (viii). En el caso de estos autores, lo que se propone es una solidaridad con sujetos que todavía están vivos; en el caso de mi investigación, la solidaridad sólo puede manifestarse con respecto a los restos arqueológicos, textos y testimonios que nos han dejado aquellos sujetos que ya no están entre nosotros, lo cual dificulta la operación y la hace más difícil de justificar. Digamos, entonces, que se trata de algo así como una solidaridad retroactiva. 
América profunda. Buenos Aires: Hachette, 1962.

López Mazz, José M. “La reconstrucción del pasado, la identidad nacional y la labor arqueológica: el caso uruguayo”. Arqueología en América Latina hoy. E. Politis, ed. Bogotá: Biblioteca Popular, 1992. 167- 175.

MacCormack, Sabine. Religion in the Andes. Vision and Imagination in Early Colonial Peru. Princeton, NJ: Princeton University Press, 1991.

Malpass, Michael A. (Ed.). Provincial Inca. Archaeological and Ethnohistorical Assessment of the Impact of the Inca State. Iowa City: University of Iowa Press, 1993.

Mignolo, Walter. The Darker Side of the Renaissance. Literacy, Territoriality and Colonization. Ann Arbor: The University of Michigan Press, 1995.

"Occidentalización, imperialismo, globalización: herencias coloniales y teorías poscoloniales”. Revista Iberoamericana 170-171 (1995): 27-40.

"Posoccidentalismo: las epistemologías fronterizas y el dilema de los estudios (latinoamericanos) de área”. Revista Iberoamericana 176-177 (1996): 679-696.

Rabasa, José y Javier Sanjinés. "Introduction: The Politics of Subaltern Studies”. Dispositio/n 46 (1994): v- xi.

Rama, Angel. Transculturación narrativa en América Latina. [1982]. Mexico: Siglo XXI editores, 1985 .

Said, Edward. “Representing the Colonized: Anthropology’s Interlocutors”. Critical Inquiry 15/2 (1989): 205-225.

Taussig, Michael. Shamanism, Colonialism, and The Wild Man. A Study in Terror and Healing. Chicago/Londres: University of Chicago Press, 1987.

Trigo, Abril. "Fronteras de la epistemología: epistemologías de la frontera”. Papeles de Montevideo 1 (1997): 71- 89. 